\title{
Crane Hook Analysis for different Cross-Section using ANSYS
}

\author{
Bhimsen Shrestha, Aashish Bhandari, Sakar Poudel and Mr. Kasi V. Rao* \\ *Research Guide
}

Department of Mechanical Engineering

Koneru Laxshmaiah Education Foundation

(Deemed to Be University)

Greenfields, Vaddeswaram, Guntur District

Andrapradesh, India

\begin{abstract}
A lifting hook is a device for grabbing and lifting loads by means of a device such as a hoist or a crane. A lifting hook is usually equipped with a safety latch to prevent the disengagement of the lifting wire rope sling, chain or rope to which the load is attached. Crane hook is always subjected to failure due to the accumulation of a large amount of stress concentration which can eventually lead to its failure. To study the stress pattern of crane hook in its loaded condition, a solid model of crane hook is prepared with the help of Solid Works 19.0 software. The pattern of stress distribution in the 3D model of the crane hook is obtained using ANSYS 19.2 software. In this present work, the obtained stresses by using finite element analysis and the WinklerBatch method in different cross-sections are compared \& to reduce the stress formed in sections by changing its design parameters (changing the mass of material in trapezoidal section). The stress concentration factors are used in strength and durability evaluation of structure and machine elements. It is observed that stress is affected if the weight is increased.
\end{abstract}

Key Words: Strain, Durability, Stress Concentration, Strength, Failure.

\section{INTRODUCTION}

A crane hook is a device for grabbing and lifting loads by means of a device such as a hoist or crane. It is usually equipped with a safety latch to prevent the disengagement of the lifting wire rope sling, chain or rope to which the load is attached.

It is one of the most important components used in various industries to carry heavy loads. This paper gives an overview of mathematical calculations with various cross section with constant load.

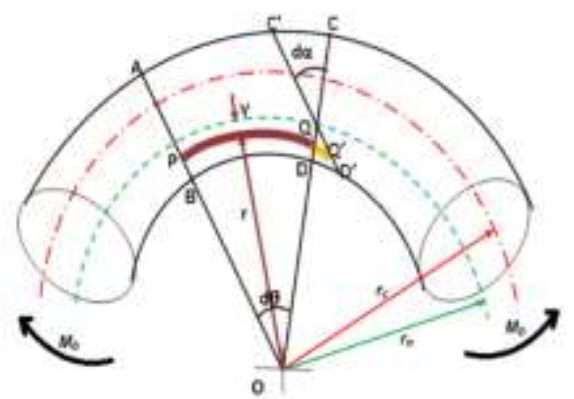

Figure 1 Geometrical bending of curved beam

At first, Solid Works design is prepared; And then, Static and structural analysis is performed on ANSYS 19.2. From the result obtained, stress induced in hook is analyzed in order to determine the factor of safety of crane hook so that possible failure can be avoided.

Hooks are available in following different cross section of area.

$>$ Circular Cross Section area 
$>$ Rectangular cross section area

$>$ Triangular cross section area

$>$ Trapezoidal cross section area

Fewer work has been done on the optimization of crane hook as the material type, cross section area and radius are design parameters that affect the weight of crane hook. In this project, stress induced in different cross section hook is analyzed in ANSYS by increasing its mass or weight suitably and then comparison has been carried out. Comparing.

\subsection{Winkler-Bach Formula for Curved Beams}

Consider a curved beam subjected to bending moment $\mathrm{Mb}$ as shown in the figure. Consider a curved beam subjected to bending moment $\mathrm{Mb}$ as shown in the figure.

1. The material of the beam is perfectly homogeneous [i.e., same material throughout] and isotropic [i.e., equal elastic properties in all directions]

2. The cross section has an axis of symmetry in a plane along the length of the beam.

3. The material of the beam obeys Hooke's law.

4. The transverse sections which are plane before bending remain plane after bending also.

5. Each layer of the beam is free to expand or contract, independent of the layer above or below it.

6. The Young's modulus is same both in tension and compression.

Let's consider the case in which beam section is symmetrical (Figure: 2) about plane of curvature and bending moment acts in it so that bending takes place in plane of curvature (Figure: 1). In order to perform mathematical analysis of stress, the curved beam flexure formula is used.

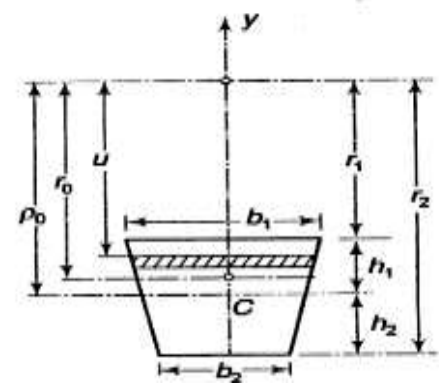

Figure 2 Parameter of Trapezoidal Section

\section{MATERIAL AND DESIGN OF CRANE HOOK}

Steel is taken as the standard material for Crane Hook as it is widely used for its manufacturing. The load carrying capacity of crane hook should be optimized. As it is subjected to vertical load it must be able to absorb deflection induced due to variable loads. This ability to absorb produced energy ensures the safety of crane.

The mechanical properties of standard steel have been tabulated below in Table 1 below.

Table 1 Mechanical Properties of crane hook

\begin{tabular}{|c|c|}
\hline Properties & Values \\
\hline Density $(\delta)$ & $7.85 \mathrm{e}-006 \mathrm{~kg} \mathrm{~mm}^{-3}$ \\
\hline Coefficient of thermal Expansion $(\gamma)$ & $1.2 \mathrm{e}-005$ \\
\hline Compressive Yield Strength MPA $\left(\sigma_{\mathrm{ys}}\right)$ & 250 \\
\hline Tensile Yield Strength Mpa $\left(\sigma_{\mathrm{ts}}\right)$ & 250 \\
\hline Temperature $(\mathrm{o} C)$ & 22 \\
\hline Poisson's ratio & 0.28 \\
\hline Shear Modulus & $7.9 \mathrm{e}+010 \mathrm{~N} / \mathrm{m}^{2}$ \\
\hline Resistivity & $1.7 \mathrm{e}-004-\mathrm{ohm} \mathrm{mm}$ \\
\hline
\end{tabular}

\subsection{Crane Hook Design}

Generally, machine structures and frame having curved portions are subjected to axial and bending loads or both of them together. The stress due to curvature become greater due to reduction in radius of curvature. As a result of which equations of straight beams when used shows different result than that what it actually has. The actual stresses may be several times greater 
for the small radius of curvature than the value obtained for straight beams. So, equation of straight beams is not applied in case of curved beam. The transverse sections which are plane before bending remain plane after bending also. Each layer of the beam is free to expand or contract, independent of the layer above or below it. In case of curve beam, the neutral surface does not coincide with centroidal axis but instead shifted towards the Centre of curvature. The design of crane hook was done by taking certain data related to load(w), C.S.A and curvatures which are generally used in industrial applications of crane hook. These data are mentioned below.

Table 2 Theoretical Calculation of crane hook in MATLAB

\begin{tabular}{|c|c|c|c|c|c|}
\hline Values & Rectangle & Circular & Triangular & Trapezoidal & T- section \\
\hline B & 140 & 140 & 140 & 140 & - \\
\hline D & 179 & 179 & 179 & 179 & - \\
\hline $\mathbf{C}$ & & & & 56 & \\
\hline $\mathbf{R}$ & 170 & 170 & 170 & 170 & 170 \\
\hline D1 & & & & 76.7143 & - \\
\hline D2 & & & & 102.2857 & - \\
\hline $\mathbf{R}_{1}$ & - & - & 80 & - & 80.5 \\
\hline $\mathbf{R}_{2}$ & - & - & 259.5 & - & 140.5 \\
\hline $\mathbf{R}_{3}$ & - & - & - & - & 220.5 \\
\hline$T 1=t 2=t 3$ & - & - & - & - & 60 \\
\hline $\mathbf{B}_{1}$ & - & - & - & - & 179 \\
\hline $\mathbf{B}_{2}$ & - & - & - & & 80 \\
\hline $\mathbf{W}$ & 50000 & 50000 & 50000 & 50000 & 50000 \\
\hline $\mathbf{A}$ & 25060 & $2.5165 \mathrm{e}+04$ & 12530 & 17542 & 15540 \\
\hline $\mathbf{H}^{2}$ & $3.02266 \mathrm{e}+03$ & $2.2801 \mathrm{e}+03$ & $1.2916 \mathrm{e}+03$ & $2.7183 \mathrm{e}+03$ & $1.1168 \mathrm{e}+04$ \\
\hline $\mathbf{M}$ & 8500000 & 8500000 & 8500000 & 8500000 & 8500000 \\
\hline$Y_{1}$ & 89.5 & 89.5 & 59.6667 & 102.2857 & 79.3 \\
\hline $\mathbf{Y}_{2}$ & 89.5 & 89.5 & 119.3333 & 76.7143 & 60.73 \\
\hline$S_{a}$ & 17.8734 & 26.0124 & 44.2940 & 42.7566 & 4.063 \\
\hline$S_{b}$ & 4.1683 & 6.6988 & 32.8348 & 6.5378 & -1.0259 \\
\hline Stress & 1.9952 & 1.9869 & 3.9904 & 2.8503 & 3.2175 \\
\hline Tensile & 19.8686 & 27.9993 & 48.2884 & 25.6069 & 7.2798 \\
\hline Compressive & 2.1730 & 4.7119 & 28.8444 & 3.6875 & -4.2434 \\
\hline
\end{tabular}

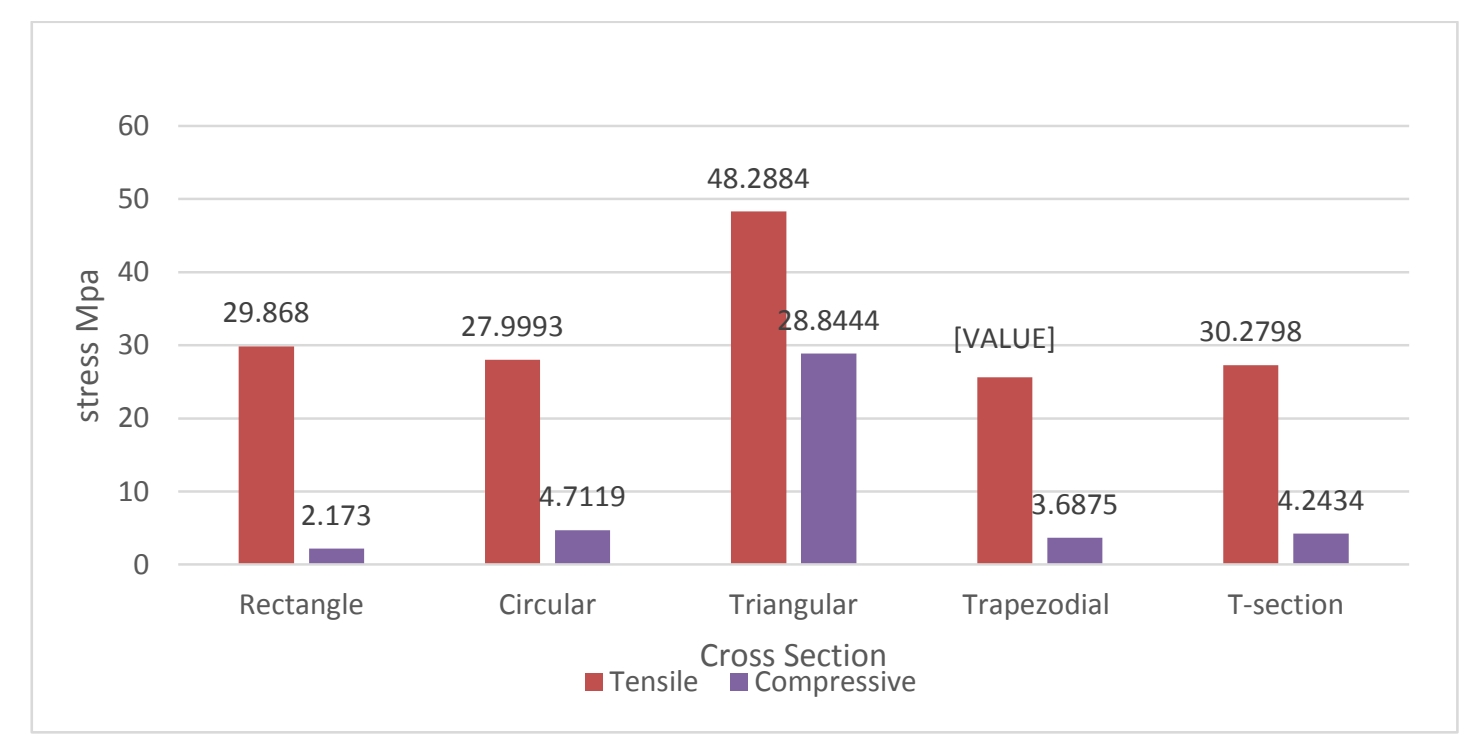

Figure 2 Tensile vs Compressive Stress Comparison

\section{MODELLING OF CRANE HOOK USING SOLIDWORKS}

Several models of crane hook are designed using solid work 2019 software and then designed model were imported to ANSYS for Finite element structural analysis. Solidworks 2019 facilities the design tasks to export to different other interface of software like ANSYS WORKBENCH. ANSYS WORKBENCH is a specific environment consisting of different set of tools, that allows the user to perform specific design tasks as well as analysis task in a particular area. And hence Workbench is preferred to perform 
the analysis of modeled hook. Solidworks 2019 facilities for Part design, Wireframe and Surface Design, Assembly Design, and Drafting Works.

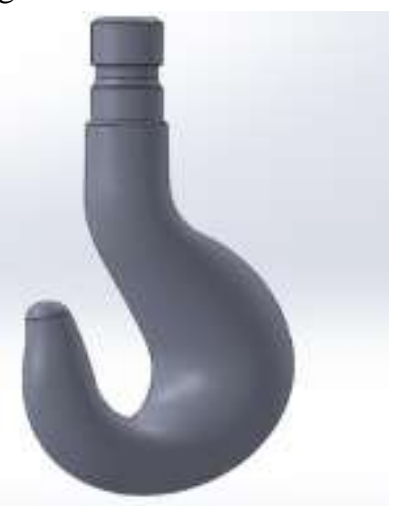

Figure 4 Crane Hook with Circular Cross section

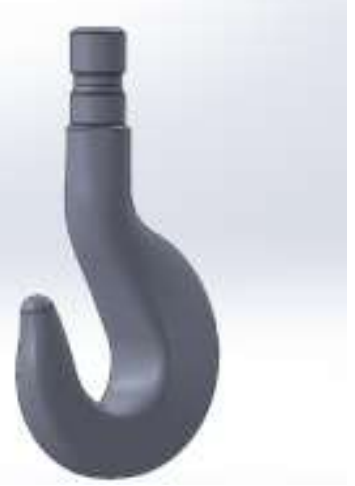

Figure 5 Crane hook with trapezoidal Cross Section

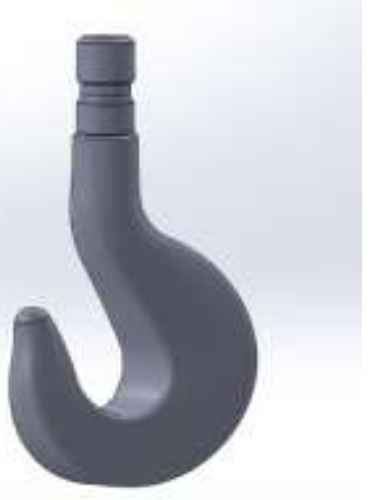

Figure 3 Crane Hook with Rectangular Cross Section

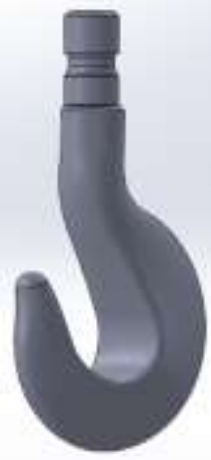

Figure Crane hook with Triangular Cross Section

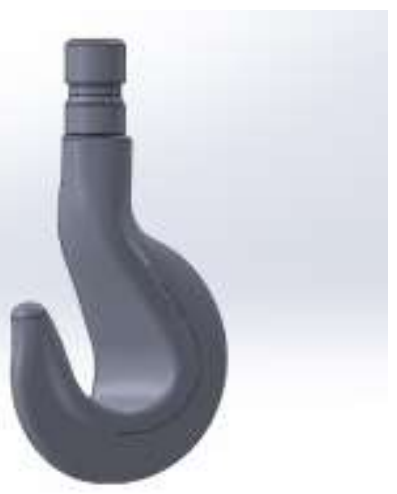

Figure Crane Hook With Tsection Cross Section

\section{FINITE ELEMENT ANALYSIS (FEA) OF CRANE HOOK USING ANSYS 2019}

The finite element method serves as a powerful tool for getting the numerical solution of wide range of engineering problems in virtual environment which helps user to estimate the design procedure. ANSYS software for structural analysis allows you to solve your most complex structural engineering projects and make superior design decisions more quickly. Finite element analysis (FEA) software from ANSYS provides engineers the ability to automate and customize simulations and even parameterize them for many design scenarios. You can easily connect ANSYS Structural Mechanics software to other physics tools for even better realism, predicting performance and behavior of even the most complex projects. Engineers throughout the industry optimize product designs with FEA software from ANSYS.

In this method of analysis, a complex structure is discretized into simple geometric shapes called finite elements. And the material properties and the governing relationships are assigned or defined for these elements and several boundary conditions were applied which should be approximately same as a real-world scenario or should be scale down. After all the conditions are setup, it gives us the approximate behavior of the continuum or the element. 
International Journal of Advances in Scientific Research and Engineering (ijasre), Vol 5 (12), December-2019

\subsection{Meshing}
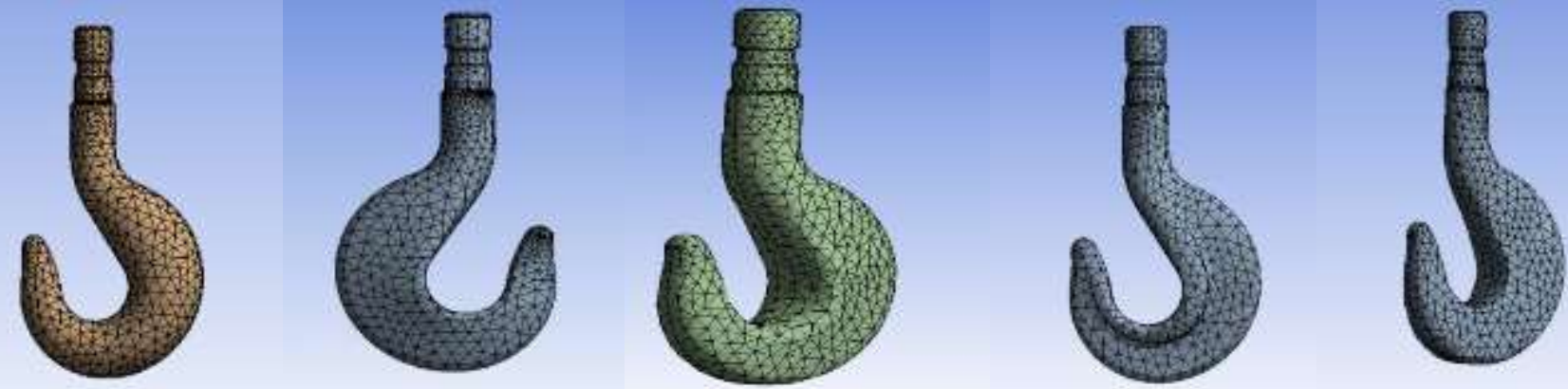

Figure 6 Meshing of circular, triangular, Trapezoidal, T- section and rectangular cross section

\section{ANSYS STRUCTURAL ANALYSIS RESULTS}

\subsection{For Circular Cross Section}
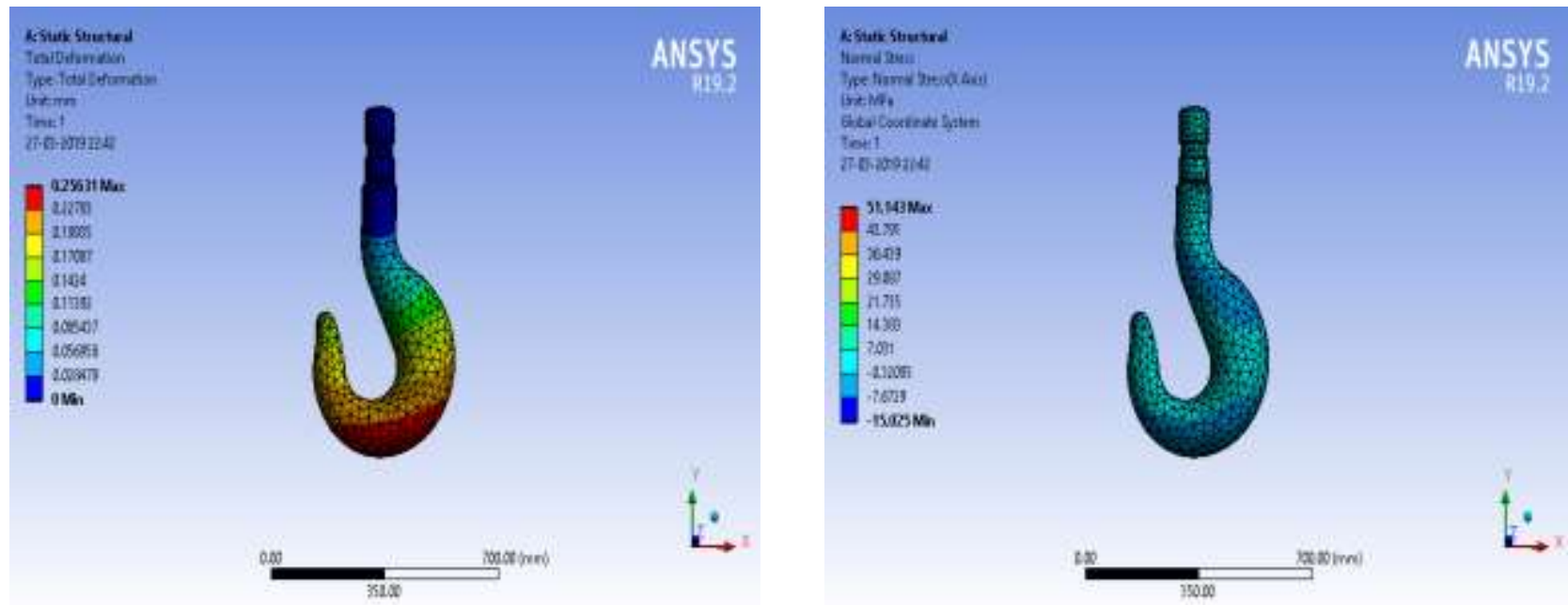

\subsection{For Triangular Cross Section}
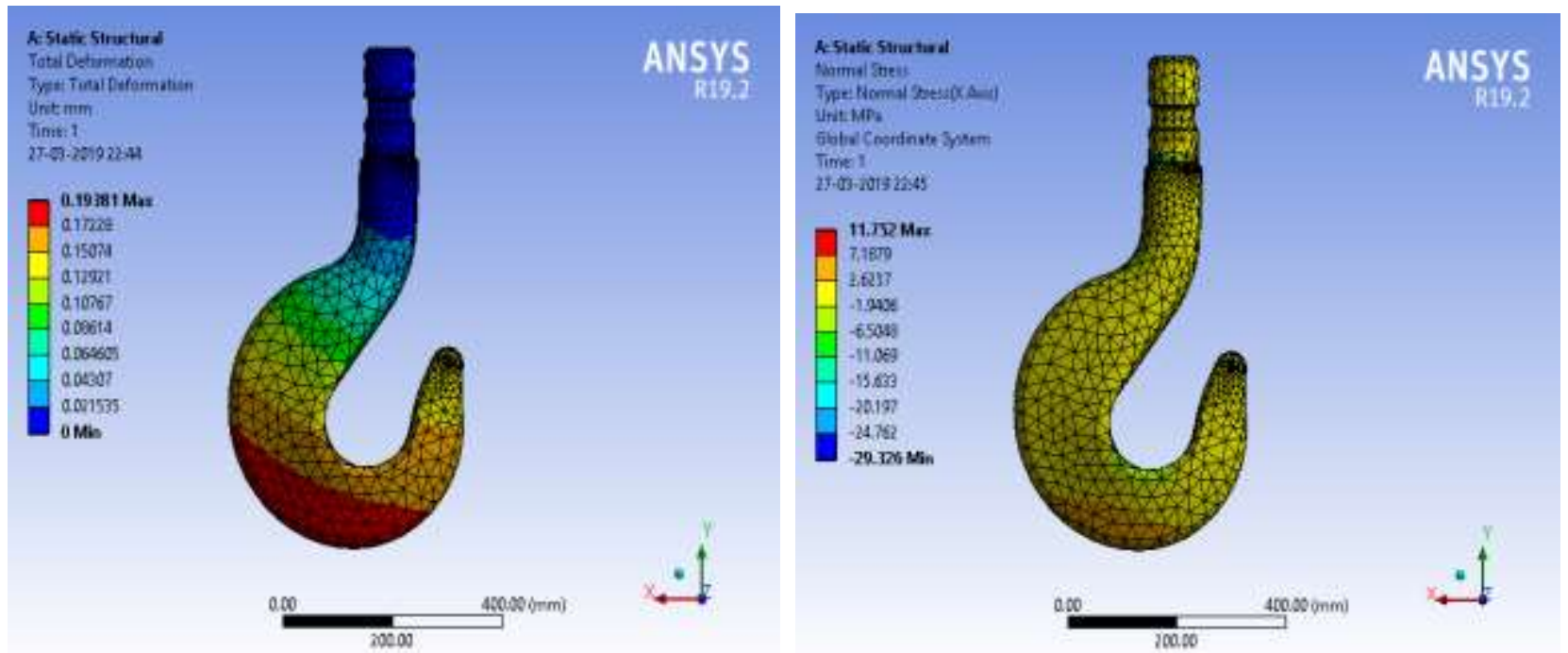
International Journal of Advances in Scientific Research and Engineering (ijasre), Vol 5 (12), December-2019

\subsection{For Trapezoidal Cross Section}
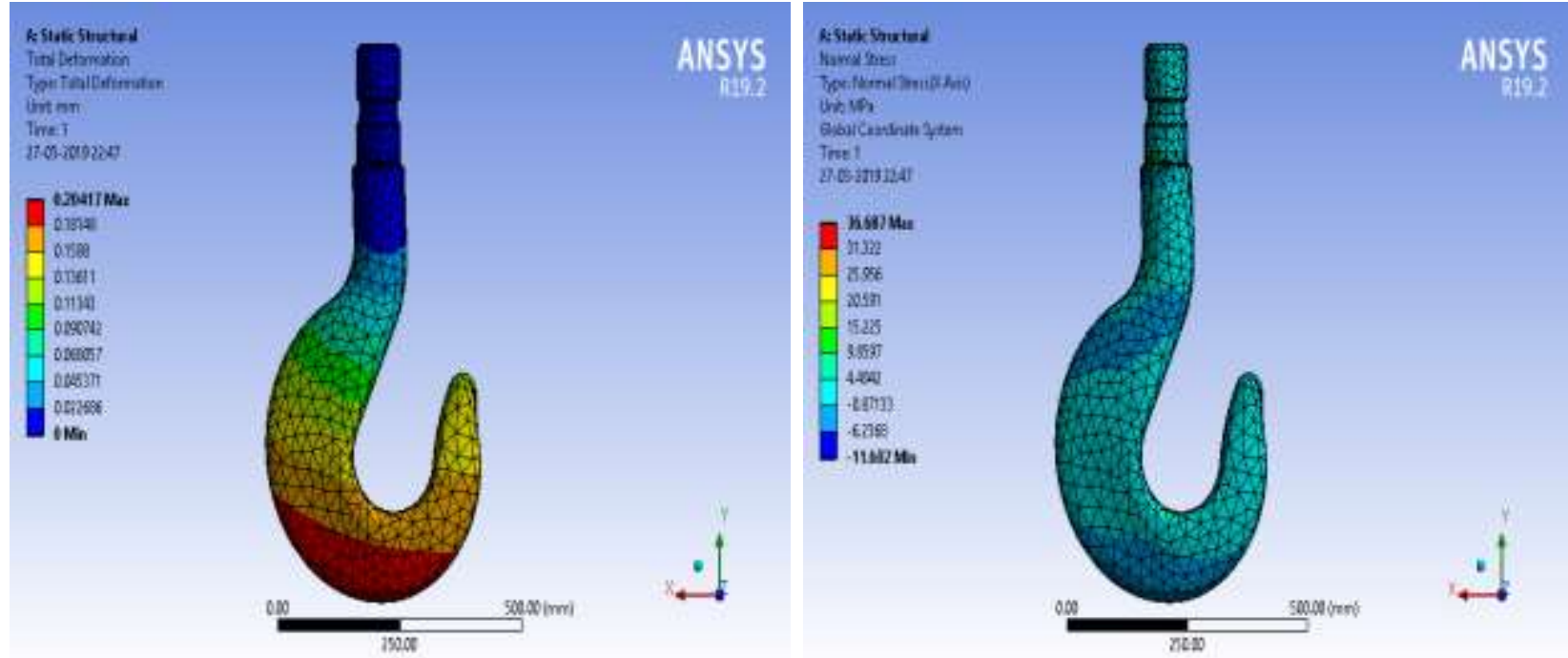

\subsection{For Rectangular Cross Section}
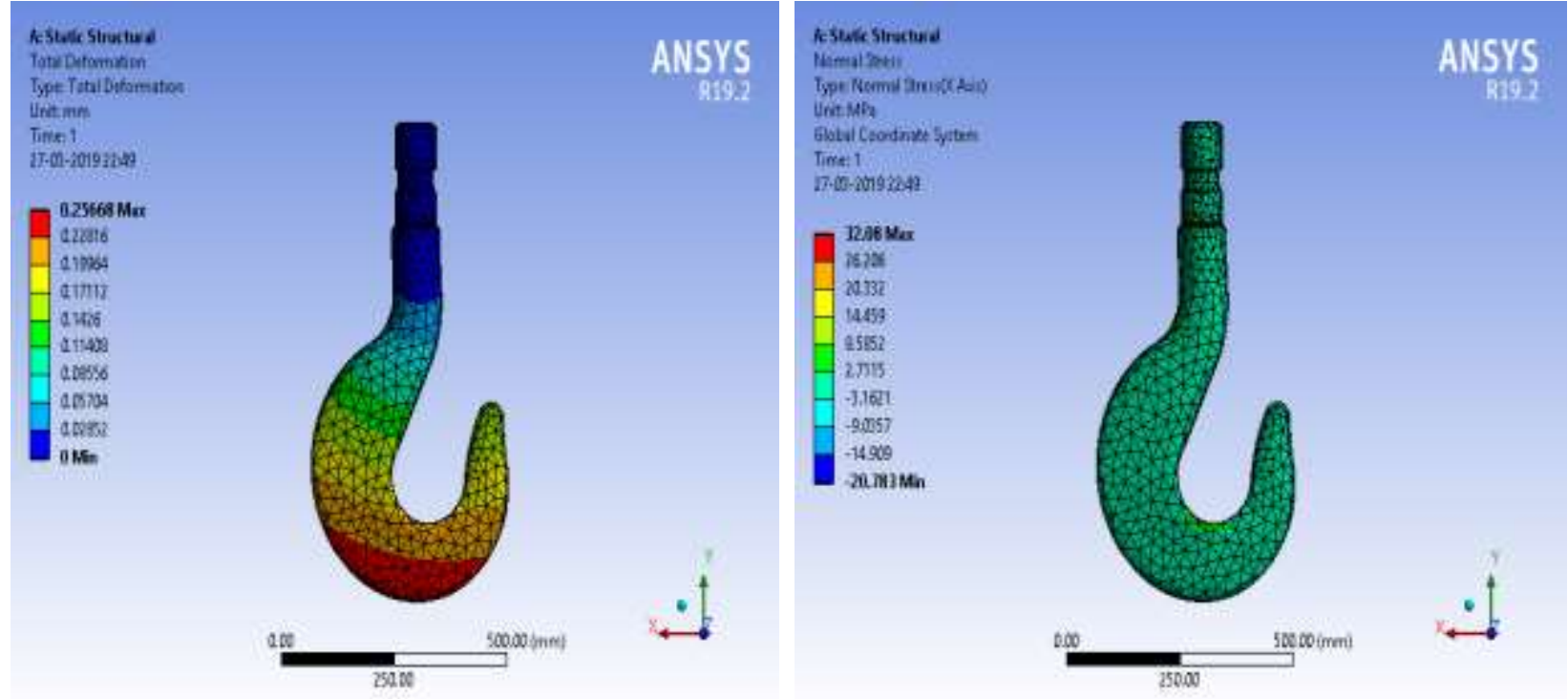

\subsection{For T-Section Cross Section}
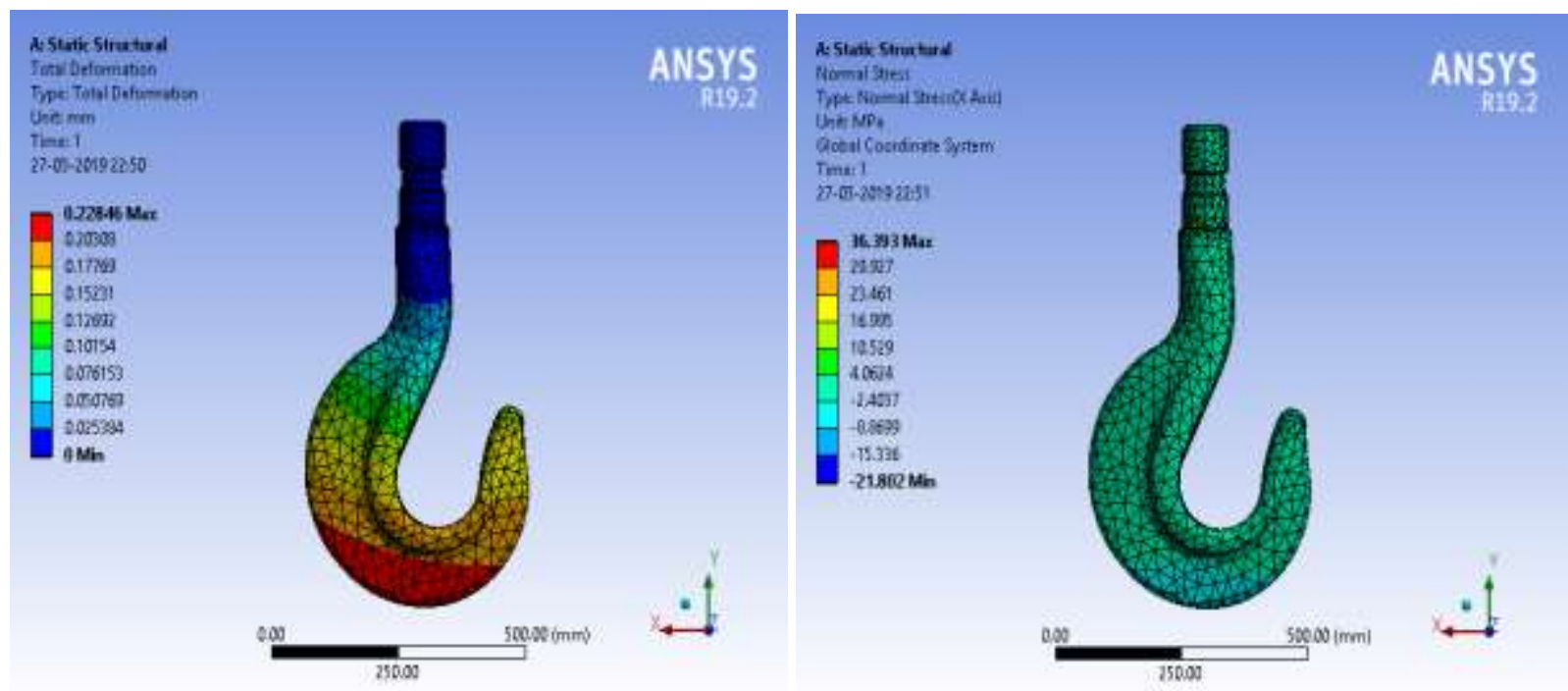


\section{RESULTS AND DISCUSSION}

In order to carryout this project, fiver different types of crane hooks with different cross section are designed and then exported to ANSYS in IGES format for the further analysis. Load of $50 \mathrm{KN}$ is applied to each crane hook in order to determine the amount of induced stress. The hook is fixed at the top end in all the three possible X, Y, and Z direction and the load of 50KN is applied at the nodes of inner curvature. And then it is allowed to perform the task through the software environment. The result of stress and deformation obtained for different cross section of Crane Hook is then tabulated on the table. This result is compared with the theoretical results. It is found that both the analytical result and theoretical results are good in agreement with little deviation on values which suggest that ANSYS can be used for analyzing the stress induced in different structures.

Load applied: - $50 \mathrm{KN}$

Structural Steel: - ISOTROPIC

Table 3 Analytical Result

\begin{tabular}{|l|l|l|l|}
\hline Type & Deformation $(\mathbf{m m})$ & $\begin{array}{l}\text { Stress at Inner Profile } \\
\text { (Mpa) }\end{array}$ & $\begin{array}{l}\text { Stress AT Outer Profile } \\
\text { (Mpa) }\end{array}$ \\
\hline Triangular & 0.19381 & 45.2536 & -2.844 \\
\hline Rectangular & 0.25668 & 32.08 & -2.173 \\
\hline T- Section & 0.22846 & 36.393 & -4.002 \\
\hline Trapezoidal & 0.20417 & 24.6069 & -3.003 \\
\hline Circular & 0.25631 & 31.143 & -5.5025 \\
\hline
\end{tabular}

\section{CONCLUSIONS}

The crane hook for five different cross section namely circular, rectangular, trapezoidal, triangular and t-section are successfully designed by using curved beam concept. The SOLID WORKS 2019 Software has been used to design the different section of hooks and ANSYS WORKBENCH is used for the analysis of stress induced in Inner and Outer Profile along with deformation. From the analysis, it is found that the stress induced in trapezoidal cross section is less than that of other four cross section which suggest that Crane Hooks having Trapezoidal are more durable and have greater capacity to absorb and store deflection produced by vertical load.

\section{REFERENCES}

1. M. Shaban, M. I. Mohamed, A. E. Abuelezz and T. Khalifa, "Determination of Stress Distribution in Crane Hook by Caustic", International Journal of Innovative Research in Science, Engineering and Technology, Vol. 2, Issue 5, May 2013.

2. Narvydas, N. Puodžiūnienè, "Circumferential stress concentration factors at the asymmetric shallow notches of the lifting hooks of trapezoidal cross- section”, ISSN 1392 - 1207. MECHANIKA. 2012 Volume 18(2): 152- 157.

3. SpasojeTrifković, NebojšaRadić et. al, "Stress analysis of crane hook using FEM", INFOTEH- JAHORINA Vol. 10, Ref. C- 2, p. 244- 248, March 2011.

4. Bhupinder Singh, Bhaskar Nagar, B.S. Kadam and Anuj Kumar, "Modeling and Finite Element Analysis of Crane Boom", International Journal of Advanced Engineering Research and Studies, Vol. I/ Issue I/October- December, 2011/ 51- 52.

5. Y. Torres, J.M. Gallardo, J. Domínguez, F.J. Jiménez E, "Brittle fracture of a crane hook", Engineering Failure Analysis 17 (2010) 38-47.

6. Takuma Nishimura, Takao Muromaki et. al, "Damage Factor Estimation of Crane Hook (A Database Approach with Image, Knowledge and Simulation)”, 4th International Workshop on Reliable Engineering Computing (REC 2010).

7. C. Oktay AZELOĞLU, Onur ALPAY, Investigation Stress of A Lifting Hook with Different Methods, "Verification of The Stress Distribution with Photo elasticity Experiments", Electronic Journal of Machine Technologies, Vol: 6, No: 4, 2009 (71- 79).

8. Yu Huali, H.L. and Huang Xieqing, "Structure- strength of Hook with Ultimate Load by Finite Element Method", Proceedings of the International Multi- Conference of Engineers and Computer Scientists, 2009 Vol II IMECS 2009, March 18 - 20, 2009, Hong Kong. 